\title{
USE OF GEOGRAPHIC INFORMATION SYSTEMS AND SATELLITE DATA FOR ASSESSING CLIMATIC RISK OF ESTABLISHMENT OF PLANT PATHOGENS
}

\author{
K.S. KIM and R.M. BERESFORD \\ Plant \& Food Research, Mt Albert Research Centre, Private Bag 92169, \\ Auckland, New Zealand \\ Corresponding author: kkim@hortresearch.co.nz
}

\begin{abstract}
Geographic information systems (GIS) have been used for geospatial data management and analysis, map production and spatial modelling. They also have the potential to incorporate climate and satellite data that could provide a spatial perspective on risk of establishment of plant pathogens. In the present case study, the climatic suitability for establishment of dwarf bunt, a disease that can cause market access restrictions, on wheat or other grass hosts in New Zealand was analysed using a GIS approach. Establishment risk for dwarf bunt in New Zealand was found to be very low. GIS was found to be a more versatile tool for modelling potential geographic distribution of organisms than conventional climate matching tools, such as CLIMEX.

Keywords: biosecurity risk assessment, dwarf bunt, Tilletia controversa, GIS, satellite, CLIMEX.
\end{abstract}

\section{INTRODUCTION}

The control of an invasive organism would be most successful when monitoring efforts are focused on the area where the organism is likely to become established. Climate matching systems, such as CLIMEX (Sutherst \& Maywald 1991), have been used to assess the likelihood of establishment of invasive species in a region. These systems quantify the similarity in climate between regions where a species has established and regions where that species may pose a biosecurity risk.

Climate matching systems have several limitations. Firstly, their use of a purely empirical match index, derived from the known geographical distribution of a species, limits the scope to include detailed knowledge on biological response of the species to climatic factors that might be critical to establishment. Secondly, it is difficult to use additional data, e.g. satellite data or outputs of climate models, in those systems. Finally, the uncertainty in disease risk predictions arising from approximations inherent in the input data and the rules is rarely considered.

An alternative approach is to use a geographic information system (GIS) that captures, stores, retrieves, analyses and presents spatial data coupled to a knowledge-based model describing the responses of the invasive organism to climatic and other factors. This approach can be used to predict the potential geographic distribution of the species.

In the present study, climatic conditions for the establishment of dwarf bunt disease, caused by Tilletia controversa Kühn, were analysed by incorporating knowledge available in published literature into a GIS. Dwarf bunt was chosen for the case study because the disease has caused serious problems in areas with extended snow cover (Johnsson 1992), which is a variable rarely incorporated in current climate matching systems including CLIMEX. Dwarf bunt has been reported in the USA, Canada, Russia, Germany, Switzerland, Italy, Austria and Sweden (Hoffmann 1982; Johnsson 1992). In 2006, the disease was observed in Latvia for the first time (Priekule 2007). The objective of the present study was to assess the risk of potential establishment of dwarf bunt in New Zealand, using this GIS approach as a case study. 


\section{MATERIALS AND METHODS}

The life cycle of $T$. controversa is initiated by teliospore germination, which can take 1-3 months. Temperature and light are major factors that influence the spore germination process (Baylis 1958). Johnsson (1992) suggested that both low temperatures during autumn and persistent snow cover during winter were associated with high incidence of dwarf bunt. Cloud cover may contribute to infection of dwarf bunt during winter (Zhang et al. 1995).

A series of rules describing conditions that are conducive to development of dwarf bunt was stated in natural language relevant to both the Northern and Southern Hemispheres, as follows:

Rule 1: temperature is cool in mid autumn, AND cloud cover is dense in the month following mid autumn OR snow cover is persistent in the 2 months following mid autumn.

Rule 2: temperature is cool in late autumn, AND cloud cover is dense in the month following late autumn $\mathrm{OR}$ snow cover is persistent in the 2 months following late autumn.

To convert these rule statements into a mathematical formula, AND and OR are defined as follows:

$$
\begin{aligned}
& C_{x} A N D C_{y}=C_{x} \cdot C_{y} \text { and } \\
& C_{x} \text { OR } C_{y}=C_{x}+C_{y}-C_{x} \cdot C_{y},
\end{aligned}
$$

where $\mathrm{C} \in[0,1]$. Using $\mathrm{Eq}(1)$ and (2), those rule statements can be rewritten for the Southern Hemisphere as follows:

$$
\begin{aligned}
& R_{1}=T I_{\text {April }} \cdot\left(C I_{\text {May }}+S I_{\text {May }} \cdot S I_{\text {June }}-C I_{\text {May }} \cdot S I_{\text {May }} \cdot S I_{\text {June }}\right) \text { and } \\
& R_{2}=T I_{\text {May }} \cdot\left(C I_{\text {June }}+S I_{\text {June }} \cdot S I_{\text {July }}-C I_{\text {June }} \cdot S I_{\text {June }} \cdot S I_{\text {July }}\right)
\end{aligned}
$$

where $R_{n} \in[0,1], T I_{x} \in[0,1], C I_{x} \in[0,1]$ and $S I_{x} \in[0,1]$ are climatic suitability indices for rule number $n$, temperature index, cloud cover index and snow cover index in a given month $x$, respectively.

The TI was determined as suggested by Sutherst \& Maywald (1985). Temperature data at high-resolution (10 arc min) obtained from the Climatic Research Unit, Norwich (New et al. 2002), were used for the calculation. The cold stress index CSI and heat stress index $H S I$ were defined as follows:

$$
\begin{array}{ll}
C S I=\left\{1+\exp \left[-0.5 \cdot\left(W T_{N}+10\right)\right]\right\}^{-1} \text { and } & \text { Eq. (5) } \\
H S I=1-\left\{1+\exp \left[-0.5 \cdot\left(W T_{X}-10\right)\right]\right\}^{-1} & \text { Eq. (6) }
\end{array}
$$

where $W T_{N}$ and $W T_{X}$ represent minimum and maximum temperatures from April to June, respectively.

In the present study, the Environmental Data Record (EDR), of which spatial resolution was about $50 \mathrm{~km}$, was used to determine the $S I$ for the Southern Hemisphere. The EDR is a microwave satellite product under the Defense Meteorological Satellite Program (DMSP) in the USA (http://www.class.ngdc.noaa.gov/). For the Northern Hemisphere, this study used snow cover data derived from satellite imagery (NOAA/NESDIS/OSDPD/ SSD 2004). The daily snow data for the Northern Hemisphere were used for the period from 1997 to 2007.

The frequency of days during which snow cover existed in a month $\left(N_{S}\right)$ was calculated using the snow data. The value of $N_{S} \in[0,1]$ was determined from May to August in New Zealand for each year from 2003 to 2008. The $N_{S}$ values were then averaged over years during which snow data were available. The snow cover index $S I$ was defined as follows:

$$
S I=\left\{1+\exp \left[-10 \cdot\left(N_{S}-0.5\right)\right]\right\}^{-1} .
$$


The $C I$ was determined using the High Resolution Infrared Sounder (HIRS) data (Wylie et al. 1994). The HIRS data contain the average frequencies of clouds over 22 years at one-degree spatial resolution. The $C I$ was defined as follows:

$$
C I=N_{C} \cdot f
$$

where $N_{C} \in[0,1]$ represents monthly frequency of clouds with visible optical depths $>6$ and where $f$ is a correction factor. Zhang et al. (1995) reported that in China about 5\% of wheat was infected by dwarf bunt under cloud cover conditions, whereas Hoffmann (1982) reported that about $60 \%$ of susceptible cultivars were infected under persistent snow cover. In the present study, the value of $f$ was assumed to be 0.08 at first. Later, the $f$ value was heuristically adjusted to 0.8 .

The risk index $I$ that represents the degree of suitability of climatic conditions for the establishment of dwarf bunt in a given area was determined as follows:

$$
I=\max \left(R_{1}, R_{2}\right) \cdot H S I \cdot C S I
$$

where $H S I$ and $C S I$ represent the heat stress index and cold stress index. The parameters for index functions including $C I, S I, H S I$ and $C S I$, were determined heuristically while that for $T I$ was determined using cardinal temperatures from Hoffman (1982), as follows: $D V 0=-2, D V 1=3, D V 2=8$ and $D V 3=15$.

\section{RESULTS}

When the risk index, $I$, was mapped, it seemed that $I$ values $>0.15$ indicated high risk of dwarf bunt establishment in USA, Canada, Russia, Latvia and Germany (Figs $1 \mathrm{a} \& 1 \mathrm{~b})$. For example, values were $>0.15$ on opposite sides of North America where the disease caused problems. In Europe, $I$ values were relatively higher, e.g. $>0.25$, in mountain areas, including Switzerland, Austria and southern Germany.

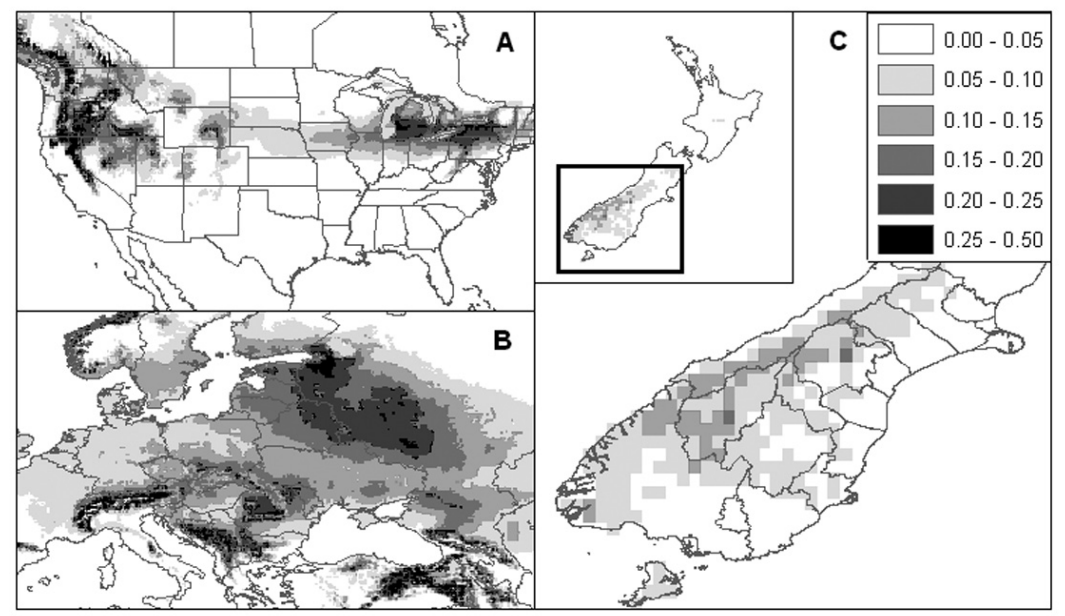

FIGURE 1: Maps showing values of the risk index, $I$, which describes climatic suitability for establishment of dwarf bunt in (a) North America, (b) Europe and (c) New Zealand. 
In New Zealand, predicted risk was greater in the South Island than the North Island (Fig. 1c). Overall, I values were relatively high in the south-western part of the South Island, where the $I$ values were between 0.1 and 0.15 , suggesting marginal risk of dwarf bunt establishment. Furthermore, the $I$ values were $>0.15$ in two areas near Lake Wanaka and Lake Tekapo.

\section{DISCUSSION}

This study suggests that the climate in New Zealand's wheat growing areas, including Canterbury, Otago and Southland regions, is unsuitable for establishment of dwarf bunt because of mild winter temperatures and a lack of persistent snow cover. Although the climatic risk for dwarf bunt may be relatively high in mountain areas in the South Island, it is unlikely to establish there because wild grasses are the only potential host plants. Purdy et al. (1963) suggested that dwarf bunt rarely occurs in grasses under natural conditions. Thus, the likelihood of dwarf bunt becoming established in these areas is negligible, unless a tremendous number of spores was imported and distributed.

The approach to climatic risk analysis used in this study had a clear advantage over other climate matching systems, e.g. CLIMEX. In the present study, snow cover and cloud cover data, which are not available in CLIMEX, were used. The rules for the climatic suitability of dwarf bunt were derived from previous observations on the disease in the literature, such as Hoffmann (1982) and Johnsson (1992). A region matching analysis in CLIMEX indicated that risk of dwarf bunt was high in China when temperature and rainfall were used as input variables and sites in the USA and Europe were used as reference sites. However, it is likely that the risk of dwarf bunt is low in China (Trione \& Hall 1986), which agrees with the results from the present approach (data not shown).

In a possible further study, the GIS approach presented in this paper could be used to assess the climatic risk of pathogens under climate change conditions. Furthermore, the present approach can be used for Monte Carlo simulation, which is useful for modelling the climatic risk with uncertainty in climate change data. Although climate matching systems including CLIMEX have been used for climate change studies (Kriticos et al. 2007), they are commonly dependent on the 30 year averages of climate variables, which make it difficult to apply a Monte Carlo approach. In contrast, the present approach could facilitate application of Monte Carlo simulation for climatic risk assessment by allowing monthly projection of the future risk of a pathogen under a different set of climate change scenarios in a given year.

\section{ACKNOWLEDGEMENT}

This work was funded by The New Zealand Foundation for Research, Science and Technology through Contract C06X0810 and MAF through Contract 23219.

\section{REFERENCES}

Baylis RJ 1958. Studies of Tilletia contraversa, the cause of dwarf bunt of winter wheat. Canadian Journal of Botany 36: 17-32.

Hoffmann JA 1982. Bunt of wheat. Plant Disease 66: 979-986.

Johnsson L 1992. Dwarf bunt (Tilletia contraversa Kühn) in winter wheat in Sweden: relationship to climate (1951-1987), climate, survey results and cultivation measures (1967-1987). Zeitschrift für Pflanzenkrankheiten und Pflanzenschutz 99: 256-265.

Kriticos DJ, Stephens AEA, Leriche A 2007. Effect of climate change on oriental fruit fly in New Zealand and the Pacific. New Zealand Plant Protection 60: 271-278.

New M, Lister D, Hulme M, Makin I 2002. A high-resolution data set of surface climate over global land areas. Climate Research 21: 1-25.

NOAA/NESDIS/OSDPD/SSD 2004, updated 2006. IMS daily Northern Hemisphere snow and ice analysis at $4 \mathrm{~km}$ and $24 \mathrm{~km}$ resolution. National Snow and Ice Data Center, Boulder, Colorado, USA. http://nsidc.org/data/g02156.html (accessed 5 May 2009). 
Priekule I 2007. First report of dwarf bunt caused by Tilletia controversa in Latvia. Plant Pathology 56: 1042.

Purdy LH, Kendrick EL, Hoffmann JA, Holton CS 1963. Dwarf bunt of wheat. Annual Review Microbiology 17: 199-222.

Sutherst RW, Maywald GF 1985. A computerised system for matching climates in ecology. Agriculture, Ecosystems and Environment 13: 281-299.

Sutherst RW, Maywald GF 1991. Climate-matching for quarantine, using CLIMEX. Plant Protection Quarterly 6: 3-7.

Wylie DP, Menzel WP, Woolf HM, Strabala KI 1994. Four years of global cirrus cloud statistics using HIRS. Journal of Climate 7: 1972-1986.

Zhang Z, Zhang CR, Wang ZZ 1995. Plant quarantine significance of dwarf bunt of wheat to China. Bulletin OEPP/EPPO Bulletin 25: 665-671. 